\title{
Risk Management in Clinical Laboratory: from Theory to Practice
}

\author{
David Remona Eliza1*, Dobreanu Minodora² \\ 1 Department of Medical Biochemistry, University of Medicine and Pharmacy Tîrgu Mureș, Romania \\ 2 Department of Laboratory Medicine University of Medicine and Pharmacy Tîrgu Mureș, Romania
}

Clinical laboratory tests ensure approximately $70 \%$ of the medical decisions, so that the time until the release of the results and its accuracy are critical for the diagnosis and the efficiency of the treatment [1]. Risk management involves both the anticipation of what could happen erroneous and the assessment of errors' frequency as well as the consequences or the severity of the effects caused by it, and finally to decide what can be done in order to reduce the risk to an acceptable clinical level. For this reason, organizations should not see the risk management as a compliance issue, but as an integral part of the decision-making process. EP23-A is a guideline of CLSI that introduces the risk management principles in the clinical laboratory and encourages the laboratories to develop plans of risk management which are addressed to the risks of each laboratory. EP18-A2 proposes 2 techniques for identifying and controlling the errors in the laboratory: FMEA (Failure Mode and Effects Analysis) and FRACAS (Failure Reporting, Analysis and Corrective Action System). The European Committee of Experts and Management of Safety and Quality in Health Care proposed to use the quality indicators to identify the critical stages of each process, thus being possible to assess continuously the medical processes with the aim of identifying the errors when they occur. This review summarizes the principles of the risk management in the clinical laboratory, thus it can achieve its aims to report valid, accurate and reliable test results

Keywords: pre-analytical error, risk management, quality indicator, FMEA

Received: 11 June 2015 / Accepted:11 August 2015

\section{Introduction}

The obligation of introducing the term of "risk management" by ISO 15189:2012, will determine us to focus on, to understand and to apply in the best way the above mentioned term.

Generally, organizations propose its aims, either to provide services either to obtain specific results. Organizations from the private system have as main purpose to obtain and to enhance values for its shareholders while the organizations from the public system have as a main goal to offer support to the population [2]. For a private medical laboratory the two goals should coexist in equal proportions because laboratory tests have an important role in medical decisions, thus the tests' results must be reliable and accurate. Whatever the purpose of the organization, the achievement of the goals is associated to uncertainty and this could be an impediment on the way to success.

"Risk is defined as the effect of uncertainty on the achievements" (SR Guide ISO 73:2010, definition 1.1) [3]. Another definition of "the risk is the combination of the probability of occurrence of harm and severity of the harm" (ISO/IEC GUIDE 51:2014, definition 3.9) [4]. Organizations can manage in a certain extent the risk that is associated to the performed activities, but sometimes insufficient for business where internal and external factors induce uncertainty on the achievement of objectives. Laboratories should pay attention to the methods that are used in order to identify the deficiencies or hazards when errors

* Correspondence to: Remona Eliza David

E-mail: eliza.david@umftgm.ro do occur and to take action to detect and prevent errors before they can affect the results. This can be done by drawing up a map of the testing process and to analyze each step of the process to identify potential risks or hazards (sample traceability through the pre-analytical, analytical and postanalytical processes). For this reason, organizations should not see risk management as a compliance issue, but as an integral part of the decision-making process [5].

Unfortunately, neither the laboratory test nor the equipment used in the laboratory are not free of errors, their occurrence being possible in the pre-analytical, analytical and post-analytical testing. Laboratory testing on patients' samples is a complex process, the occurrence of errors being possible at any time during the testing process. Thus, laboratories must ensure the accuracy and reliability of the results which are delivered to the patients [6].

"The risk is expressed as a combination between the consequences of an event (including the circumstances changes) and the plausibility of occurrence" (SR Guide ISO 73:2010, definition 1.1, note 4) [3]. There is a wide range of risks, from very low risks to very high risks, because there is no risk-free activity. Events with a low level of severity, but with a frequent occurrence involve higher risks, and events with high severity even if they are isolated cases involve very high risks. So, the role of lab directors is to keep the risk at an acceptable level for laboratory clinicians, patients and for our own organization $[7,8]$.

The evaluation of the conditions that can lead to the errors' occurrence, the prevention of errors before they occur and the analyze of errors can be achieved by applying the risk management in the clinical laboratory. EP23-A is a 
guide of "Clinical Laboratory Improvement Amendments" (CLIA), which introduces the principles of risk management in the clinical laboratory, borrowing concepts applied in industry and encouraging the laboratories to develop plans concerning the risk management, mainly the inherent risks specific to each laboratory activity [9]. Once the risks have been identified, the laboratory must implement continuous monitoring and control processes, in order to be sure that the risk is kept at a clinically acceptable level $[10,11]$.

According to SR Guide ISO 73:2010, definition 2.1, "risk management is described by coordinated activities which have as a purpose to direct and control an organization concerning the risk" [3]. Risk management involves anticipation of what it could happen erroneous, the assessment of the frequency of these errors as well as the consequences or the severity of the effects caused by it, and finally to decide what can be done in order to reduce the risk to an acceptable level.

Most of the standards and guidelines concerning risk management are directed towards the equipment and reagents manufacturers, but there is not enough information about the risk management applied in clinical laboratories. However, it's possible to borrow the industrial principles of risk management in order to reduce the errors in a clinical laboratory. Risk management is a new concept for clinical laboratories [5].

For the moment, there are few guidelines such as CLSI EP18-A2, "Risk management techniques to identify and control error sources", CLSI EP23-A, "Laboratory quality control based on risk management" or ISO/TS 22367, "Medical laboratories - Reduction of error through risk management and continual improvement", which allow the implementation of risk management in the clinical laboratory. According to SR ISO Guide 73:2010, definition 3.1, "the risk management is defined as the systematic application of policies, procedures and management practices in the activities of communication, consultation, in establishing the context and also to identify, to analyze, to assess, to treat, to monitor and correct the risk. Risk assessment is a global process that includes the risk identification, analyze and assessment" (SR ISO Guide ISO 73:2010, definition 3.4.1) [3].

Risk identification is the first step in drawing-up a risk register in an organization and includes two stages: the initial identification of risks and the continuous and permanent identification of them. The initial identification is done in the following situations: when the organization has not previously identified its risks in a systematic form, when the organization is recently established or when it's about developing a project or a new activity within the organization. Continuous and permanent identification is necessary in order to identify the risks that have not previously manifested or to identify the modified risks that have already existed, but they are no more important for the organization [2].
SR Guide 73:2010 defines the following concepts:

1. "Risk identification is the process of discovery, recognition and description of the risks. Risks' description is a structural presentation and it contains four elements: sources, events, causes and consequences."

2. "Source of risk is the element that alone or in combination with other elements, has the potential to cause an inherent risk."

3. "The event is the appearance or change of a particular set of circumstances."

4. "The consequences are the effect of an event which affects the objectives" [3].

The identified risks must be related to the organization's objective and it must also be done according to a specific approach or using a certain tool. One of the approaches is to conduct a risk analysis by an internal or contracted team, which will analyze all the operations and activities of the organization that are related to its objectives and then it will identify the associated risks. Another approach is the self-risk assessment when every department of the organization analyzes its own activities, contributing in this way to the identification of the risks they face. This latter approach has the advantage that obliges/requires the risk managers to be more aware and more responsible when identifying the risks themselves [2].

Methods of identifying risks may include:

1. Documented methods, for example lists to check and to review historical data. When there is a long enough history, based on this it's possible to identify the risk sources, to assess the tendencies and to predict the future "evolution" of the failures/losses/non-conformities.

2. Systematic approach, the expert team follows-up a systematic process to identify the risks with the help of a question set addressed to the company's management and to department's level.

3. Reasoning techniques such as FMEA, FTA (Fault Tree Analysis) or FRACAS.

4. Technical support to improve the accuracy and the integrity of risks' identification, particularly the brainstorming sessions with the participation of several departments' representatives and Delphi methodology.

Regardless of the techniques that are used to identify the risks, is necessary to pay attention to the human and organizational factors because their variations/changes should be included in the risk identification process, besides the hardware and software events [12].

"Risk analysis is the process of understanding the nature of the risk and to determine the risk level (SR Guide ISO 73:2010, definition 3.6.1)". Risks analysis means to establish the consequences and probabilities when the risks may occur given the presence/absence and efficiency of any control types. The risks' consequences and probabilities are subsequently combined to establish a risk level.

EP18-A2 proposes 2 techniques for identifying and con- 
trol the errors in the laboratory: FMEA and FRACAS [13].

FMEA is for identifying the potential sources of errors, determining the probability and the consequences of each error, and also the occurrence mechanisms presenting the control measures in order to detect and eradicate these errors. From this point of view FMEA is considered to be pyramidal anterograde approach [13].

There are several uses of FMEA: Design FMEA - which is used for components or products, System FMEA- which is used for systems, Process FMEA - which is used for the manufacturing and assembling process, Service FMEA and Software FMEA [12].

FMEA can be applied to processes and procedures being used to identify the medical errors potential from the medical systems and in the errors recorded in the maintenance system.

FMEA assures start points to other analyze techniques like analyze of FTA (Fault Tree Analysis), from the point of view of quality or quantity. Manufacturers usually apply FMEA when a process, product or service is designed or in the situation when a process or product already existing on the market may be applied in more specialties. It is the responsibility of the manufacturer to remove any source of errors for the customer as well as to provide recommendations about how to control or how to manage these errors. In the clinical laboratory FMEA should be applied before a new testing or installing new equipment. The laboratory should consult the user manual provided by the manufacturer in order to get knowledge of the already identified errors and then to highlight the potential hazards specific to the laboratory during the various stages of the process and to establish the control measures with the aim to prevent these hazards. FMEA needs detailed information about the system's elements in order to perform a correct and complete analyze of the errors that may appear [5].

"FMEA includes the following stages:

- to define the aim and objectives;

- to build up the team;

- to divide the process in elements and parts;

- to define the role of each component or step;

- to identify for each element or step the conditions the errors may occur, the mechanisms that lead to these occurrence, the effects and consequences of these errors as well as the possibilities of detecting the errors;

- to identify the prevention methods and to minimalize the errors from clinical point of view" [12].

The common methods are: critical condition index (it is applied to equipment's, these having the same consequences), the risk level (applied to equipment or to processes, and it is obtained by combining the consequences with the probability of the errors occurrence), the number of priority risk - RPN (obtained by multiplying the numbers of the scales for consequences, occurrence probability and errors detectability.

A similar revision technique of the probable errors source is to analyze the FTA, this being a retrograde approach which starts with the supposition of a high level risk and then to determine the cause of the error. This technique is useful when are analyzed multiple errors and its defects at a certain level of the system. FMEA and FTA should be applied together to assess all the possible failure paths and also the modalities to reduce them. Laboratory tests ensure approximately $70 \%$ of the medical decisions, so that the time until the release of the results and its accuracy are critical for the diagnosis and the efficiency of the treatment [1]. Although laboratory errors rate is small in comparison with the performed examinations, its importance for the health and safety of the patients are relevant [14].

There is an uncertainty related to the application of FMEA in the clinical laboratory and it's because this uncertainty requires experience and multidisciplinary teamwork. The required information is not always available. The interfaces transcend the laboratory competences involving other medical specialties. There is also a reticence of the employees concerning changes [5].

Like any other organizational innovation, FMEA should be in depth understood before being introduced into practice. There are 5 stages in its introduction:

- phase 1 - the initial contact with FMEA, during this period the tool and its applications are only partially understood;

- phase 2 - the learning stage of FMEA when we are aware of its importance;

- phase 3 - the proper built up of FMEA with improvements in its preparation and without the application of the action plans;

- phase 4 - managers realize that preventive actions identified by FMEA help to change the systems and processes, improving in this way their work and products;

- phase 5 - the processes have been adopted and FMEA becomes subject of insecurity [1].

In the clinical laboratory all the errors must be quantified and controlled by the means of quality indicators. According to ISO 15189: 2013, the Lab Director should implement quality indicators to monitor and assess periodically the lab's involvement in patients' care $[7,8,15]$. The European Committee of Experts and Management of Safety and Quality in Health Care proposed to use the quality indicators to identify the critical stage of each process, thus being possible to assess continuously the medical processes with the aim of identifying the errors when they occur. In this way ISO/TS 22367 supports the non-conformities, errors and incidents identifying in the clinical laboratory, with an emphasis on the pre-analytical and post-analytical process. These processes are the most critical and the most difficult ones to manage, involving the participation of several specialists, organizations and nursing centers [16].

Classification of non-conformities, errors and incidents occurred in the processes to which are subjected the specimens, may include the following aspects, but they are not limited to these: 
- The pre-analytical process is approximately $46-68.2 \%$ of the errors of the examination process:

1. incorrect identification of the patient;

2. mislabeling of samples;

3. incorrect homogenization of samples;

4. incorrect blood sampling;

5. incorrect tube for sampling or incorrect storage;

6. improper or prolonged transport conditions;

7. Non-conformity of serum/plasma - lipemia, hemolysis, jaundice $[14,16]$.

- The analytical process is $7-13 \%$ of the errors of the examination process:

1. procedural non-conformity;

2. errors of equipment or reagents;

3. there are discrepancies in the results of the internal control;

4. delay in analyzing the samples $[14,16]$.

- The post-analytical process is $18.5-47 \%$ of the errors of the internal control:

1. incorrect result;

2. introducing incorrectly the results in the system;

3. result sent to a different patient;

4. ambiguous way of communicating the result;

5. lack of information about the limits concerning the results' interpretation $[14,16]$.

In this study we describe the quality indicators in the pre-analytic process, acccepted by the most of the experts, the errors being grouped up to the critical or major risk of the patient. Errors are clasified according to RPN, which allows us to prioritise the risks and also to determine which risk level is accepted in the clinical laboratory. This number is obtained by multiplying the scores for the assessment of the occurence frequency, the severity and the probability of errors' detection. RPN limit where actions like prevention, minimizing or excluding the risk are essential, must be established by the laboratory. (The laboratory should decide the assessing scale of frequency, the severity and errors detection, this being different for each test) $[1,17]$.

There have been identified three main categories of errors:

- Critical errors - resulting mainly from the means used to communicate and record an analyze request, having serious consequences for the health of the patient if they were not early detected and corrected.

- Major errors - resulting from the improper application of the sampling procedure

- Minor errors - considered so, because of the low probability of occurrence, the higy probability of detection or low/absent severity. These errors are taken into account only with the purpose to review the procedure and the technical instruction [17].

1. Defining quality indicators the pre-analytical process:

2. Critical error in identifying the patient, when the staff is manually introducing the analyze request in the informatic system. Critical errors can compromise the safety of the patient. These errors can come from outside the laboratory (a request for a patient incorrectly identified and/or an incorrect identification of a sample) or within the laboratory because of an inadequate application of the sampling procedure.

3. Critical error in transcripting the analyze is considered any record error of the sample: the lack of the analyze or the incorrect introduction of a test in request.

4. Incorrect sample type when the sample has been collected in the wrong tube type or the wrong type of sample has been collected. (exemple: for prothrombine time test, blood has been collected in an EDTA tube or plasma sample instead the serum sample for determination of vitamin $\mathrm{B}_{12}$ ).

5. Incorrect fill level means an incorrect blood sampling for the coagulation test (PT, PTT, INR, fibrinogen) and hematology test (complete blood count - CBC).

6. Hemolyzed samples are considered any samples where one or more tests were not performed or one or several results were rejected or not reported because of the hemolysis.

7. Clotted samples are the sampled blood in tubes with EDTA or citrate which shows clots that are noticed by direct examination.

8. Unsuitable conditions of transportation and storage, like: biochemistry and cytology samples were stored overnight at room temperature before the analysis; the samples were not frozen and centrifuged on time; inadequate transport temperature; delayed transportation which interferes with the determination of the requested test. [17, 18, 19, 20]

The IFCC Working Group on "Laboratory Errors and Patient Safety" (WG-LEPS) developed a list with quality indicators (QIs) [21].

Table I presents the formulas for the calculation of preanalytical indicators $[17,18,21]$.

\section{Risk estimation}

For each identified error is estimated the probability of the risk occurence, but also the impact if the error will be real. The probabilityofriskoccurenceismeasuredonascaleof" improbable/remote/occasional/probable/frequent", the impact as severity level is measured on a sclae of " insignificant/minor negligible/serious/critical/catastrophic" and the detectability is measured on a scale of "low/high". There is no an absolute standard for the risk estimation, but the organization must find the most suitable strategy concerning the level of analysis [11]. The combination between the frequency and severity of errors, allows the laboratory to estimate the critical level of the error. Critical condition allows the laboratory to analyse first of all the high risk errors and to determine the acceptability level of the low risk errors $[10,11]$. These aspects are illustrated in Table II.

For a better understanding of the above mentioned information there we describe the following example: 
Table I. Formulas for the calculation of pre-analytical indicators

\begin{tabular}{|c|c|}
\hline Quality indicator & Formulas for calculation \\
\hline Critical error in identifying the patient & Number of misidentified samples $X 100 /$ Total number of samples \\
\hline Critical error of test transcription & Number of requests with erroneous data entry (test name) $X 100 /$ Total number of requests \\
\hline Inadequate container & Number of inadequate containers for each sample types $X 100 /$ Total number of requests \\
\hline Incorect fill level & Number of samples with insufficient sample volume X 100/Total number of samples \\
\hline Hemolyzed samples & Number of hemolyzed samples $X 100 /$ Total number of requests \\
\hline Clotted samples & Number of clotted samples X 100/Total number of requests \\
\hline Unsuitable conditions of transportation and storage & $\begin{array}{l}\text { 1. Number of samples that were not properly stored before analysis } X 100 / \text { Total number of samples } \\
\text { 2. Number of samples damaged during transportation } X 100 / \text { Total number of samples } \\
\text { 3. Number of samples transported at inappropriate temperature } X 100 / \text { Total number of samples } \\
\text { 4. Number of samples with excessive transportation time } X 100 / \text { Total number of samples }\end{array}$ \\
\hline
\end{tabular}

- An intense hemolyzed sample can lead to a high level of seric potassium. If the hemolysis is not mentioned on the patient's medical bulletin, the clinician may mistakenly interpret the increased potassium level resulting in the patient's injury caused by an inappropriate treatment. Errors which involve incorrect results or delays in receivinng the patients' results and they can influence the medical decisions, are considered more severe than the errors that do not lead to the modification or the confirmation of the patiennt's treatment. The injury level is defined using a semiquantitative scale of severity, ranging from negligible injuries -that can cause incovenients or a temporary discomfort- until critical or catastrophic injuriescausing a permanent deterioration of the patients's health or even his death- [11].

\section{Risk control}

After identifying the errors in the testing process and after the estimation of critical risk conditions, the laboratotry selects thre proper control measures in order to mantain the risk at an acceptable level from clinical point of view.
QC (Quality Control) aims to monitor the performance of the measuring system and informs the laboratory when the errors occur because they coul limit the use of a test result from the point of view of clinical utility.

\section{Conclusions}

Risk management is a practice developed in industrial and manufacturial environment, the new guides having as a purpose to introduce the risk management principles in the clinical laboratory. Risk mangement can minimize the possibility of errors occurrence and ensures the accuracy of tests' results. Risk management guidelines recommends that the laboratory should have a proactive role in minimizing the potential errors by developing a QCP (Quality Control Plan) individualized [9]. The laboratory should create its own testing process to identify the weakness of each testing stage. As risks are identified, the laboratories select the appropriate control processes to detect and to prevent the occurrence of errors. All errors and control processes are mentioned in the QCP (Quality Control Plan). Once implemented, the efficiency of the QCP in the laboratory should be continually monitored and revised as the

Table II. Exemples concerning the quantification methods of probability, severity and detectability

\begin{tabular}{|c|c|c|c|c|c|}
\hline & Common Terms & Rating & Practical example 1 & Practical example 2 & ER EN ISO 14971:2009 \\
\hline \multirow[t]{5}{*}{ Probability of occurrence } & Frequent & 5 & More than $1 /$ week & Daily & $1 / 1,000$ \\
\hline & Probable & 4 & Once every few months & Weekly & $1 / 10,000-1 / 1,000$ \\
\hline & Occasional & 3 & Once a year & Monthly & $1 / 100,000-1 / 10,000$ \\
\hline & Remote & 2 & Once every few years & $\begin{array}{l}\text { It may appear between 1-6 } \\
\text { weeks }\end{array}$ & $1 / 1,000,000-1 / 10,000$ \\
\hline & Improbable & 1 & Unlikely to ever happen & Annually & $1 / 10,000,000-1 / 1,000,000$ \\
\hline \multirow[t]{5}{*}{ Severity } & Catastrophic & 5 & Result in patient death & Result in patient death & Result in patient death \\
\hline & Critical & 4 & $\begin{array}{l}\text { Results in permanent injury of life- } \\
\text { threatering injury }\end{array}$ & $\begin{array}{l}\text { Results in permanent injury of } \\
\text { life-threatering injury }\end{array}$ & $\begin{array}{l}\text { Results in permanent injury of } \\
\text { life-threatering injury }\end{array}$ \\
\hline & Serious & 3 & $\begin{array}{l}\text { Results in injury or impairment requir- } \\
\text { ing professional medical intervention }\end{array}$ & $\begin{array}{l}\text { Results in injury or impairment } \\
\text { requiring professional medical } \\
\text { intervention }\end{array}$ & $\begin{array}{l}\text { Results in injury or impairment } \\
\text { requiring professional medical } \\
\text { intervention }\end{array}$ \\
\hline & Minor negligible & 2 & $\begin{array}{l}\text { Results in temporary injury or impair- } \\
\text { ment not requiring professional medi- } \\
\text { cal intervention }\end{array}$ & $\begin{array}{l}\text { Results in temporary injury or } \\
\text { impairment not requiring profes- } \\
\text { sional medical intervention }\end{array}$ & $\begin{array}{l}\text { Results in temporary injury or } \\
\text { impairment not requiring pro- } \\
\text { fessional medical intervention }\end{array}$ \\
\hline & Insignificant & 1 & $\begin{array}{l}\text { Inconvenience or temporary dis- } \\
\text { comfort }\end{array}$ & $\begin{array}{l}\text { Inconvenience or temporary } \\
\text { discomfort }\end{array}$ & $\begin{array}{l}\text { Inconvenience or temporary } \\
\text { discomfort }\end{array}$ \\
\hline \multirow[t]{5}{*}{ Detectability } & Low & 5 & Control is ineffective & Control is ineffective & Control is ineffective \\
\hline & & 4 & Control less likely to detect the failure & $\begin{array}{l}\text { Control less likely to detect the } \\
\text { failure }\end{array}$ & $\begin{array}{l}\text { Control less likely to detect the } \\
\text { failure }\end{array}$ \\
\hline & & 3 & $\begin{array}{l}\text { Control may or may not detect the } \\
\text { failure }\end{array}$ & $\begin{array}{l}\text { Control may or may not detect } \\
\text { the failure }\end{array}$ & $\begin{array}{l}\text { Control may or may not detect } \\
\text { the failure }\end{array}$ \\
\hline & & 2 & $\begin{array}{l}\text { Control almost always detects the } \\
\text { failure }\end{array}$ & $\begin{array}{l}\text { Control almost always detects } \\
\text { the failure }\end{array}$ & $\begin{array}{l}\text { Control almost always detects } \\
\text { the failure }\end{array}$ \\
\hline & High & 1 & Control can detect the failure & Control can detect the failure & Control can detect the failure \\
\hline
\end{tabular}


other errors are identified, making sure that the patients' outcome are credible, and the residual risk is mentioned at a clinically accepted level $[11,22]$.

\section{References}

1. Mendes ME, Persio de Almeida RE, Romano P and al. Practical aspects of the use of FMEA tool in clinical laboratory risk management. J Bras Patol Med. 2013; 49(3): 174-181.

2. The Orange BooK. Management of Risk - Principles and Concepts. Norwich. HM Treasury on behalf of the Controller of Her Majesty? Stationery Office. 2004

3. Asociația de Standardizare din România (ASRO). SR Ghid ISO 73:2010. Managementul riscului - Vocabular. Acest standard este identic cu ghidul internațional ISO GUIDE 73:2009. 2010

4. International Organization for Standardization ISO/IEC GUIDE 51:2014. Safety aspects - Guidelines for their inclusion in standards. Geneva. Published in Switzerland. 2014

5. Njoroge WS, Nichols HJ. Risk Management in the Clinical Laboratory. Ann Lab Med. 2014;34:274-278.

6. Lippi G, Guidi GC. Risk management in the preanalytical phase of laboratory testing. Clin Chem Lab Med. 2007; 45(6):720-727.

7. International Organization for Standardization. SR ISO 31000:2010. Managementul riscului. Principii și linii directoare. 2010

8. International Organization for Standardization. SR BS 31100:2013. Managementul riscului. Cod de practică și îndrumare pentru implementarea standardului SR ISO 31000. 2013

9. Clinical and Laboratory Standards Institute (CLSI). EP23-A-WB: A Practical Guide for Laboratory Quality Control Based on Risk Management. USA

10. Clinical and Laboratory Standards Institute (CLSI). EP23-A-WS: A Sample Form for Laboratory Quality Control Based on Risk Management. USA

11. Clinical and Laboratory Standards Institute (CLSI). EP23-ATM:
Laboratory Quality Control Based on Risk Management; Approved Guideline. USA. 2011

12. Asociația de Standardizare din România (ASRO). SR EN 31010, CEI/ ISO 31010. Managementul riscului. Tehnici de evaluare a riscurilor. Acest standard este identic cu standardul european EN 31010:2010. 2011

13. Clinical and Laboratory Standards Institute (CLSI). EP18-A2: Risk Management Technigues to Identify and Control Laboratory Error Sources; Approved Guideline - Second Edition. USA. 2009

14. Plebani M. Errors in clinical laboratories or errors in laboratory medicine? Clin Chem Lab Med. 2006;44(6):750-759.

15. International Organization for Standardization. ISO 15189:2012. Medical laboratories - Requirements for quality and competence. 2012

16. International Organization for Standardization. ISO/TS 22367:2008. Medical laboratories - Reduction of error through risk management and continual. Geneva. Published in Switzerland. 2008

17. Gimenez-Marin A, Rivas-Ruiz F, Perez-Hidalgo MM and all. Preanalytical errors management in the clinical laboratory: a five-year study. Biochemia Medica. 2014; 24:248-257.

18. Plebani M, Sciacovelli L, Chiazza ML. Harmonization of the pre-analytical quality indicators. Biochemia Medica. 2014; 24:105-103.

19. Plebani M, Sciacovelli L, Chiazza ML. Towards harmonization of quality indicators in laboratory medicine. Clin Chem Lab Med. 2013;51:187195.

20. Plebani M, Astion ML, Barth $\mathrm{JH}$ and al. Harmonization of quality indicators in laboratory medicine. A preliminary consensus. Clin Chem Lab Med. 2014;52:951-958.

21. Working Group: Laboratory Errors and Patient Safety of IFCC Education and Management Division. Membership: Laura Sciacovelli, Mario Plebani, Isabel Garcia del Pino Castro, Giuseppe Lippi, Zorica Sumarac, Keila Furtado Veira, Jamie West, Agnes Ivanov.

22. International Organization for Standardization. ER EN ISO 14971:2009. Dispozitive medicale. Aplicarea managementului de risc la dispozitivele medicale. 2011 